\title{
The correlation between Indonesian university students' receptive vocabulary knowledge and their reading comprehension level
}

\author{
Dang Arif Hartono and Stefanus Angga Badara Prima \\ ${ }^{1}$ Entrepreneurship Program, Universitas Agung Podomoro, APL Tower Lt. 5, Jl Letjen S. Parman Kav. 28, \\ Jakarta, Indonesia \\ ${ }^{2}$ Hotel Business Program, Faculty of Tourismpreneur, Universitas Agung Podomoro, APL Tower Lt. 5, \\ Jl Letjen S. Parman Kav. 28, Jakarta, Indonesia
}

\begin{abstract}
While the literature has shown that vocabulary mastery affects reading comprehension, only a few Indonesian researchers investigated this. To narrow this gap, this study aims to: 1) measure Indonesian university students' knowledge of receptive vocabulary, 2) measure their reading comprehension level, and 3) investigate the association between the two variables. The participants in this study were 168 first-year university students from a private university implementing English-medium instruction (EMI). We utilized the updated vocabulary level test to measure their receptive vocabulary size and the IELTS academic reading test to measure their reading comprehension level. The participants mean scores on the updated VLT were 28.73, 26.63, 22.27, 22.42 and 23.12 at the 1,000, 2,000, 3,000, 4,000, and 5,000-word level respectively. Only 34 out of 168 participants could be considered to have a sufficient vocabulary size. On average they scored $16.08(S D=7.96)$ on the IELTS academic reading test, which was roughly equivalent to 5 in IELTS band score. We also found strong and significant correlations between the participants' scores on the IELTS academic reading test and the updated VLT at all levels, with the largest effect size on the 4,000-word level $(r=.71, p<.001$, BCa 95\% CI [0.64, 0.78], $\left.r^{2}=.50\right)$. These findings indicated that the participants did not have sufficient vocabulary knowledge and had a low reading proficiency, potentially inhibiting progress in their academic pursuits. We discussed the findings in relation to the teaching of English in EFL, ESL, and EMI contexts. Practical implications of the findings are also discussed.
\end{abstract}

Keywords: English-medium instruction; IELTS; receptive vocabulary; Vocabulary Levels Test

\section{First Received:}

17 December 2020

Final Proof Received: 23 May 2021
Accepted:

12 April 2021

Published: 31 May 2021

How to cite (in APA style):

Hartono, D. A. \& Prima, S. A. B. (2021). The correlation between Indonesian university students' receptive vocabulary knowledge and their reading comprehension level. Indonesian Journal of Applied Linguistics, 11(1), 21-29. https://doi.org/10.17509/ijal.v11i1.34590

\section{INTRODUCTION}

Reading is considered an important predictor of achieving academic success, both in the first language (L1) and the second language settings (L2) (Rosenfeld et al., 2001). At universities, the ability to read in second or foreign languages, especially English, is becoming increasingly important since the majority of learning materials at the university level are written in English. To obtain satisfactory results in their studies, university students must have good reading proficiency.

One of the factors affecting reading comprehension is vocabulary knowledge. Its role is so critical that Schmitt (2000) emphasized that vocabulary knowledge is at the heart of communicative competence and language

\footnotetext{
*Corresponding Author

Email: dang.hartono@ fulbrightmail.org
} 
acquisition. Acquiring a large number of vocabulary is crucial for second language learners because they need to know most of the words in a text or a conversation to comprehend it (Gonzalez-Fernandez \& Schmitt, 2017). Furthermore, Grabe (2009) maintained that it is important for second language learners to have sufficient vocabulary to read well because reading facilitates further language acquisition.

Researchers have long tried to identify the amount of vocabulary English language learners should acquire. Nation and Waring (1997) asserted that language learners need to know 3,000-5,000word families to ensure comprehension. Vocabulary at the 1,000 to 3,000-word levels (also known as beginner vocabulary or high-frequency words) is a minimum requirement for reading comprehension (Schmitt \& Schmitt, 2014). Language learners at the intermediate level master the vocabulary at the 4,000 to 5,000-word levels and advanced language learners master the vocabulary at the 6,000 to 9,000 word levels (Nation \& Meara, 2010). Similarly, Schmitt et al. (2011) argued that English language learners must acquire the vocabulary at the 8,000 to 9,000-word levels to be able to read various types of texts with ease. Furthermore, Nation (2006) found that learners must know 8,000 to 9,000-word families to comprehend a variety of texts independently. In terms of percentage, Schmitt et al. (2011) maintained that learners must know at least $98 \%$ of all the words within academic texts to comprehend them. Schmitt et al. (2017) later suggested that understanding $95-98 \%$ of the words used in a text is an acceptable threshold for reading comprehension.

These findings imply two things. First, having a sufficient vocabulary size, as indicated by the high percentage of vocabulary one should know, is crucial to ensure reading comprehension. Second, mastering vocabulary at different levels of word families (e.g. 1,000 to 9,000) is equally important.

Although it is clear that vocabulary mastery is important to support reading, there is still limited research on how much English vocabulary is mastered by Indonesian university students. Only a handful of studies have examined this issue. The earliest study was conducted by Nurweni and Read (1999) in which they measured the vocabulary size of 324 freshmen at a university in Sumatra using translation test, word associates test, and interview. They found that on average the participants knew 1,226 English words. Another study conducted by Kurniawan (2017) involved 202 freshmen at a university in Sumatra. From the study, he found that on average first-year university students knew 1,400 words. Susanto (2017), in his study involving 30 undergraduate students, found that only $1 \%$ of the students had acquired vocabulary at the 2,000-word level. The most recent study by Siregar (2020) found that the average vocabulary size of 40 freshmen at a private university in West Java was only 8,732.5 word families and only 10 of them had mastered the vocabulary at the 1,000 to 5,000 -word levels.

The findings in these studies indicate a general trend, but they should be taken with caution as there are some methodological issues. Nurweni and Read (1999) devised their tests based on the General Service List (developed in 1953) and the University Word List (developed in 1984). Similarly, in his study, Kurniawan (2017) utilized the vocabulary size test that was developed using the same General Service List. Since these lists were created decades ago, it is questionable whether the words included in them are truly reflective of the language people use nowadays.

Susanto's (2017) study also has at least three issues. First, the number of subjects who participated in the study was quite small, which was only 30 people. Second, to measure the participants' level of vocabulary mastery, he used the old version of the VLT developed by Schmitt et al. (2001). Xing and Fulcher (2007) criticized this version of VLT because it was based on the list of words considered out of date. Third, because the old version of VLT only measures vocabulary size at the 2,000, 3,000, 5,000, and 10,000-word levels, the results from Susanto's study did not paint a complete picture as they missed the most basic-but-important level $(1,000)$ and another component of the intermediate levels (4,000). Around 65-85\% of English words used in spoken and written communication are the words from the 1,000-word families (Webb \& Nation, 2017), so missing this information potentially obscures our judgment about the true ability of the participants from the study. The same also applies to the words at the 4,000-word level. L2 learners need to master the vocabulary at the intermediate levels $(4,000-8,000)$ to facilitate them in learning using authentic teaching materials (Schmitt \& Schmitt, 2014). Since Susanto's study did not fully capture the participants' mastery at this level, then we are left only with partial information about their ability to comprehend authentic texts.

Siregar (2020) already utilized the most recent version of VLT: the updated Vocabulary Levels Test developed by Webb et al. (2017). However, her study could have provided more convincing results if it employed a larger pool of samples.

This study is not only aimed to address the issues from the previous studies in the Indonesian context but also to contribute to the literature of vocabulary research by examining the relationship between vocabulary mastery at different levels and reading comprehension. In this study, we tried to narrow the gap in the literature by answering the following questions:

1. To what extent do Indonesian university students master the vocabulary at the 1,000 to 5,000 -word levels? 
2. What is the reading comprehension level of Indonesian university students as measured by the IELTS academic reading test?

3. To what extent does Indonesian university students' mastery of vocabulary at the 1,000 to 5,000 -word levels correlate to their performance on the IELTS academic reading test?

\section{METHOD \\ Context}

This study was conducted at a private university in Jakarta. The university maintains a close connection with a reputable college in Wellesley, Massachusetts, USA. The students at this university can spend the first two years of their undergraduate studies in Jakarta and then transfer to the college to spend their junior and senior years in Wellesley. Due to this nature of cooperation, from its inception, the university has been implementing Englishmedium Instruction (EMI) policy.

EMI demands both the lecturers and the students at the university to be relatively fluent in English. Many of the lecturers are western-educated and have no difficulty in delivering their lessons in English. However, some of them think that the students do not seem to be at the level which prepares them for EMI. Thus, this study was a response to the concerns raised by some of the lecturers. In this study, we investigated the students' vocabulary size and their reading comprehension level to find out whether or not they are ready for EMI.

\section{Participants}

The population in this study were 228 first-year university students from a small, private university in Jakarta. A total of 168 students were selected using the convenience sampling method from 6 intact classes. Their ages ranged from 16 to 22, with an average of 19.11. All the participants enrolled in a compulsory rhetoric and composition course. It is important to note that, in this context, it was not possible to apply random sampling because the participants were grouped into classes based on their respective majors (Hospitality Business, Entrepreneurship, and Accounting). Nevertheless, because the number of samples was quite large ( $75 \%$ of the total population), then the chance of sampling error is low and the level of sample representativeness of the population increases (Dornyei, 2007; Riazi, 2016). These would assure the generalizability of the results toward the studied population.

\section{Instruments}

The Vocabulary Levels Test is a tool designed specifically to measure receptive vocabulary knowledge of English language learners. Initially, it was developed by Paul Nation in the 1980s (Kremmel \& Schmitt, 2017) and later updated and validated by Schmitt et al. (2001). This version of VLT measures learners' vocabulary size at the 2,000, 3,000, 5,000, and 10,000-word families (the leveling is based on how frequent words are used in communication, i.e., words at the 2,000-word level are more frequently used than those at the 3,000word level). Recently, the test has been re-updated and validated. This latest version of VLT is called the updated Vocabulary Level Test. It was developed and validated by Webb et al. (2017) as an attempt to improve the previous version of VLT. Webb et al. (2017) developed two versions (version $\mathrm{A}$ a nd B) of the test that are of equal difficulty.

In this study, we utilized the updated VLT version B. Unlike its previous version, the updated VLT measures learners' mastery of English vocabulary at 1,000 to 5,000-word levels. According to Webb et al. (2017), it was purposefully designed that way to help teachers measure their students' learning progress. Therefore, it can be more useful than the previous version that is unable to measure vocabulary size at the foundational level $(1,000$ word families) and the intermediate level (4,000word families). The updated VLT has 5 levels, with each measuring the vocabulary size at 1,000, 2,000, 3,000, 4,000, and 5,000-word families respectively. Each level contains 10 clusters. In each cluster, there are 6 words and test-takers must match 3 of them with their most fitting descriptions or definitions, leaving out the remaining 3 words designed as distractors. Therefore, for each level, the minimum score one can obtain is 0 and the maximum score is 30 . Webb et al. (2017) explained that this test was designed to measure vocabulary size at different levels of word families, so accumulating the scores obtained from 1,000 to 5,000-word levels would be of no use.

The updated VLT can be completed in less than an hour, but Webb et al. (2017) maintained that test-takers may be given an hour to complete it. The test has been widely accepted and used by researchers in different contexts (e.g. Dang, 2020; Durbahn et al., 2020; Sun \& Dang, 2020).

To measure the participants' reading comprehension level, we utilized a reading test taken from the academic module of the Cambridge IELTS 10 book (Cambridge English Language Assessment, 2015). The book, which was written by the developer of the IELTS test, claims to contain authentic IELTS examination papers. Therefore, we argue that the validity, reliability, and psychometric properties of the IELTS academic reading test used in this study are ensured. The academic reading test module contains 3 reading passages and 40 questions. Thus, the maximum number of raw points one can obtain is 40. In an official IELTS test, these raw points are converted into band scores of 1 to 9 . However, in this study, we decided to use the raw 
scores to maintain accuracy in the statistical calculations.

\section{Data collection procedure}

To avoid the risk of fatigue that might affect the participants' performance, the updated VLT and the IELTS reading test were administered at different times. The participants were given the updated VLT on February 25, 2020, and the IELTS reading test a week later. They were asked to complete the updated VLT and the IELTS reading test during class hours to reduce the chance of subject attritions. The participants were given an hour to complete the updated VLT. To simulate the official IELTS test, they were also given an hour to complete the reading test. Additionally, we required them to indicate on their answer sheet if they had taken an IELTS preparation course or the official IELTS test previously. We decided to do this to see if familiarity with the IELTS test format or previous experience with the test preparation course would make a difference in the participants' performance. All the IELTS reading answer sheets were then scored against the answer key provided in the Cambridge IELTS 10 book. The participants' answers on the updated VLT were also scored using an answer key obtained from S. Webb (personal communication, February 18, 2020).

\section{Data analysis}

The data were tabulated in Microsoft ${ }^{\circledR}$ Excel and then analyzed using IBM $^{\circledR}$ SPSS version 20 . We employed robust statistics to obtain descriptive statistics and inferential statistics (Pearson product- moment correlation coefficient). This was to follow the latest best practice of data analysis in second language research advocated by many researchers (Larson-Hall, 2015; Plonsky, 2015; Plonsky et al., 2014). Robust statistics relies "on the techniques of parametric statistics but use computer-intensive techniques to eliminate the requirement that data be normally distributed" (Larson-Hall, 2015, p. xvi). It is "robust to violations of assumption" and is more powerful than the parametric and non-parametric statistics (Larson-Hall, 2015, pp. 74-76). To be specific, the robust statistics we utilized in this study was a technique called bootstrapping.

Bootstrapping is "a Monte Carlo resampling procedure designed to simulate sampling distribution" that is normally only attainable from employing a large number of samples, so it produces results that are "more stable and statistically accurate" as they are not affected by non-normal distributions and low statistical power (Plonsky et al., 2014, p. 1). Following the suggestions from LaFlair et al., (2015), the bootstrapping applied in this study used these specifications: using a simple sampling method, running 10,000 times of resampling, and calculating bias-corrected and accelerated (BCa) 95\% confidence interval (CI).

\section{FINDINGS AND DISCUSSION}

Table 1 below details the findings from the study. As can be seen from the table, the participants' scores on the updated VLT decrease as the levels increase, except for the 5,000-word level.

Table 1

Descriptive Statistics (with Bootstrapping)

\begin{tabular}{|c|c|c|c|c|c|c|}
\hline \multirow[t]{2}{*}{ Variable } & \multirow[t]{2}{*}{ Min } & \multirow[t]{2}{*}{ Max } & \multirow[t]{2}{*}{$M$} & \multicolumn{2}{|c|}{ BCa $95 \%$ CI for $M$} & \multirow[t]{2}{*}{$S D$} \\
\hline & & & & $\mathrm{LL}$ & UL & \\
\hline Age & 16 & 22 & 19.11 & - & - & 0.77 \\
\hline IELTS Reading & 2 & 38 & 16.08 & 14.89 & 17.31 & 7.96 \\
\hline UVLT 1,000 & 12 & 30 & 28.73 & 28.40 & 29.02 & 2.26 \\
\hline UVLT 2,000 & 12 & 30 & 26.63 & 25.98 & 27.23 & 4.12 \\
\hline UVLT 3,000 & 7 & 30 & 22.27 & 21.36 & 23.16 & 6.07 \\
\hline UVLT 4,000 & 7 & 30 & 22.42 & 21.60 & 23.26 & 5.41 \\
\hline UVLT 5,000 & 7 & 30 & 23.12 & 22.38 & 23.80 & 4.73 \\
\hline
\end{tabular}

Note: $N=168 ; \mathrm{CI}=$ confidence interval; $\mathrm{LL}=$ lower limit; $\mathrm{UL}=$ upper limit.

In percentage, the participants' vocabulary mastery was $95.77 \%$ at the 1,000-word level, $88.77 \%$ at the 2,000 -word level, $74.23 \%$ at the 3,000 -word level, $74.73 \%$ at the 4,000 -word level, and $77.07 \%$ at the 5,000-word level.

According to Webb et al. (2017), to be considered having sufficient vocabulary, English language learners must obtain a minimum score of 29 at the 1,000, 2,000, and 3,000-word levels. At the 4,000 and 5,000-word levels, they should at least score 24 . When these criteria applied, only 34 out of 168 participants managed to reach the recommended minimum score at all levels. On average, they scored $30,29.88,29.32,28.44$, and 27.68 at the
1,000 to 5,000-word level respectively. This means that only $20.24 \%$ of the participants could be considered to have a sufficient vocabulary size.

The participants' mean score on the IELTS academic reading test was $16.08(S D=7.96), \mathrm{BCa}$ 95\% CI [14.89, 17.31]. Out of 168 participants, 12 indicated that they had either taken the official IELTS test or had enrolled in an IELTS preparation course previously. A separate calculation revealed that this group's mean score was $19.08(S D=8.14)$, BCa 95\% CI [15.92, 24.42]. Although initially we were interested to see whether previous experience or familiarity with the IELTS test format would make a difference, we decided not to make a 
comparison between this small group and the remaining participants because its small number would not produce a statistically meaningful result.
Table 2 shows the correlations between the participants' scores on the updated VLT and the IELTS reading test.

Table 2

Pearson Product Moment Correlation Matrix between Variables (with Bootstrapping)

\begin{tabular}{|c|c|c|c|c|}
\hline \multirow{2}{*}{ Measure } & \multirow{2}{*}{$\begin{array}{c}\text { IELTS } \\
\text { Reading }\end{array}$} & \multicolumn{2}{|c|}{ BCa 95\% CI for $r$} & \multirow[t]{2}{*}{ Effect size $\left(r^{2}\right)$} \\
\hline & & $\mathbf{L L}$ & UL & \\
\hline UVLT 1,000 & $.340 * *$ & .14 & .55 & .12 \\
\hline UVLT 2,000 & $.570 * *$ & .49 & .64 & .32 \\
\hline UVLT 3,000 & $.681 * *$ & .61 & .75 & .46 \\
\hline UVLT 4,000 & $.713^{* *}$ & .64 & .78 & .50 \\
\hline UVLT 5,000 & $.634 * *$ & .55 & .71 & .40 \\
\hline
\end{tabular}

Note: $* * p<.001 ; \mathrm{CI}=$ confidence interval; $\mathrm{LL}=$ lower limit; $\mathrm{UL}=$ upper limit

It revealed that their performance on the 3,000, 4,000, and 5,000-word levels correlated strongly with their performance on the IELTS academic reading test.

\section{To what extent do Indonesian university students master the vocabulary at the 1,000 to 5,000 -word levels?}

Table 1 shows that on average the participants' scored $28.73,26.63$, and 22.27 at the $1,000,2,000$, and 3,000-word levels respectively. These figures are still below the minimum score of 29 . The table also reveals that their mean scores at the 4,000 and 5,000-word levels were 22.42 and 23.12 respectively. Again, these figures did not reach the minimum score of 24. In short, these findings indicate that the participants' English vocabulary size, both at the basic levels $(1,000,2,000$, and $3,000)$ and intermediate levels (4,000 and 5,000), was still below the recommended minimum score.

These results paint a discouraging picture, especially when we consider the fact that the participants had completed 12 years of compulsory education (elementary to high school). In Indonesia, we can expect that one at least studies English for 6 years, starting from junior high school to senior high school. In Jakarta, English is commonly taught even earlier in many schools, starting from year 3 or year 4 at elementary schools. These findings reveal that only a small percentage of high school graduates have sufficient vocabulary size to prepare them for university.

While the results are concerning, they are not entirely surprising. They corroborated the findings from Susanto (2017) whose study found that students at a private university in Batam on average only scored 18 at the 2,000-word level and 14 at the 3,000-word level. In a similar fashion, Siregar (2020) also found that students at a private university in West Java had a similarly small size of vocabulary and only 10 out of 40 students managed to reach the recommended minimum score at all levels. However, compared to the findings in this study, Susanto's (2017) and Siregar's (2020) findings are even more alarming because the participants in their study were English major students.

Because previous studies in the Indonesian context provided a similar picture, we think it is worthwhile to make a comparison with studies conducted abroad within a similar, EFL setting. Ataş (2018) measured the vocabulary size of 33 undergraduate students in Turkey and found that on average they scored $27.21,22.76$, and 18.00 at the 2,000, 3,000, and 5,000-word levels respectively. Dang (2020) investigated the vocabulary size of 442 Vietnamese EFL learners from non-English majors. She found that, on average, the students scored below the expected minimum standard: 27.73 at the 1,000-word level, 19.96 at the 2,000-word level, 13.11 at the 3,000-word level, 10.23 at the 4,000word level, and 7.95 at the 5,000-word level. The results from these studies are comparable to our findings.

As various studies conducted in EFL settings (e.g. Indonesia, Turkey, Vietnam) have shown that English language learners have a small size of vocabulary, one might assume that this might be caused by the lack of target language input in EFL contexts. Exposure to the target language is a key factor to ensure L2 vocabulary learning (Webb \& Nation, 2017). Yet, in many cases, learners in EFL settings only use English in their classroom. Since they can communicate with each other using their mother tongue or the official language of their country, using English in daily communications does not seem to be natural. This, in turn, might potentially hamper the acquisition of the target language.

While this reasoning seems logical, studies in the literature suggest that settings (EFL or ESL) may not be the cause of this trend. A study conducted in Malaysia (Ibrahim et al., 2016) with 360 undergraduates found that on average they scored 26.82, 24.03, and 16.46 at the 2,000, 3,000, and 5,000-word levels respectively. In Hong Kong, $\mathrm{Li}$ and MacGregor (2010) measured the vocabulary size of 128 university students majoring in English at undergraduate and postgraduate levels. They found that the participants knew $97.4 \%$ and $92.2 \%$ of the words at the 2,000 and 3,000-word levels, but 
only $77.8 \%$ of the words at the 5,000-word level. Using the recommended minimum scores set by Webb et al. (2017) as a standard, we could see that the participants from the study conducted by Ibrahim et al. (2016) did not reach the minimum threshold at the 2,000, 3,000, and 5,000-word levels. Similarly, the participants from Li and MacGregor's (2010) study only managed to satisfy the minimum standard at the 2,000-word level. Therefore, these two studies indicate that learners in ESL settings also had difficulty achieving the recommended minimum score. This is surprising, considering that English is one of the official languages used for business and educational purposes in Malaysia and Hong Kong. Thus, it is still inconclusive whether low vocabulary size among university students is a trend exclusively taking place in EFL settings or it is a trend shared by learners in both ESL and EFL settings. Further research is needed to answer this conundrum.

Another possible explanation why university students in Indonesia have such a small vocabulary size is because the teaching of English in EFL settings does not put a strong emphasis on the acquisition of high-frequency words (Dang, 2020). In Indonesia, under the Competency-based Curriculum (implemented in 2004) and the Schoolbased Curriculum or the Kurikulum Tingkat Satuan Pendidikan (implemented in 2006), the teaching of English put a strong emphasis on communicative competence, leaving linguistic competence (e.g. knowledge of vocabulary, grammar, etc.) at the periphery (Cahyono \& Widiati, 2015). Because there was no standardization on how vocabulary teaching must be conducted and what words must be taught, teachers had to decide on their own what vocabulary their students need to learn (Cahyono \& Widiati, 2015). The 2013 curriculum (or commonly called K13) encourages the use of authentic materials, which potentially fosters vocabulary acquisition. However, in reality, teachers felt that K13 is textbook-driven (Nur \& Madkur, 2014). Also, K13 formally introduces English as a compulsory subject in junior high school and gives liberty to elementary schools to decide whether or not they will offer the subject to students. This means that some students will not likely receive formal English instruction until they are 12 or 13 years old. In sum, issues with the national curricula may contribute to Indonesian university students' small size of English vocabulary.

Regardless of what the real causes might be, one thing we are confident to conclude is that a low level of vocabulary knowledge potentially inhibits reading comprehension and learning, especially in an EMI context. Encountering too many unfamiliar words within a textbook impedes EMI students' reading comprehension (Uchihara \& Harada, 2018). In contrast, language learners' lexical knowledge has been found to strongly correlate with their academic achievement (Szabo et al., 2020). Therefore, it is imperative for learners, especially university students in EMI settings, to have sufficient vocabulary size.

What is the reading comprehension level of Indonesian university students as measured by the IELTS academic reading test module?

Table 1 shows that the average score of the participants on the IELTS reading test is 16.08. This figure is roughly equivalent to band 5 when converted into the IELTS band scale. It is commonly known that the minimum IELTS reading score required for entry to universities in Englishspeaking countries ranges from 6 to 6.5. Thus, this finding means that the participants' reading comprehension level was still low because it was still 1 to 1.5 bands lower than the minimum standard commonly required to gain admission as an undergraduate student at universities abroad.

Schmitt et al. (2011) found that English language learners need to know about $98 \%$ of the words in academic texts to ensure comprehension. However, our findings show that the participants' vocabulary mastery was only $95.77 \%$ at the 1,000 word level, $88.77 \%$ at the 2,000-word level, $74.23 \%$ at the 3,000-word level, $74.73 \%$ at the 4,000 -word level, and $77.07 \%$ at the 5,000-word level. This indicates that their receptive vocabulary knowledge was far lower than the recommended $98 \%$. Furthermore, L2 learners need to master the vocabulary at the intermediate levels $(4,000-8,000)$ to facilitate them in learning from authentic teaching materials (Schmitt \& Schmitt, 2014). Because the readings in the IELTS academic module are comparable to authentic materials one can find in newspapers, magazines, etc., then logically the participants should master the vocabulary at the intermediate levels to help them comprehend the reading passages in the IELTS academic reading test. Yet, our finding shows the participants' vocabulary mastery at the intermediate levels $(4,000$ and 5,000-word level) was less than $78 \%$. Therefore, it should not be surprising that they performed poorly on the IETLS academic reading test.

These findings are discouraging because studies have found that IELTS scores strongly correlate with academic performance (Woodrow, 2006; Yen \& Kuzma, 2009). In fact, in EMI settings, researchers have found that language proficiency, as measured by standardized tests, is a strong predictor of academic achievement (Aizawa et al., 2020; Rose et al., 2020). Thus, to ensure students have a higher chance of success in their academic life, universities implementing EMI should set a minimum proficiency level (at least in reading and listening) as one of their admission criteria. Providing English language courses for 
students with low English proficiency can also be an alternative solution.

To what extent does Indonesian university students' mastery of vocabulary at 1,000-5,000 levels correlate to their performance on the IELTS academic reading test?

Table 2 shows positive and significant correlations between the updated VLT score at all levels and the IELTS academic reading score. Three findings are particularly noteworthy. First, the correlation between the participants' score on the 3,000-word level and IELTS academic reading test was found to be strong and significant $(r=.68, p<.001)$ with a narrow BCa 95\% CI [ 0.61, 0.75] and a strong effect size $\left(r^{2}=.46\right)$. Next, the highest correlation found was the correlation between the participants' IELTS academic reading scores and their scores on the updated VLT at the 4,000-word level $(r=.71, p$ $<.001)$, with a close BCa 95\% CI [0.64, 0.78] and a large effect size $\left(r^{2}=.50\right)$. Finally, the correlation between the participants' scores on the 5,000-world level and the IELTS academic reading test was also significant and strong $(r=.63, p .<.001)$ with a relatively close $\mathrm{BCa} 95 \% \mathrm{CI}[0.55,0.71]$ and a large effect size $\left(r^{2}=.40\right)$.

These findings are noteworthy not only because they revealed strong correlations between the participants' scores on the two tests, but also because of their large effect sizes. As much as $46 \%$, $50 \%$, and $40 \%$ of the participants' performance on the IELTS academic reading test can be predicted by their performance on the VLT's 3,000, 4,000, and 5,000-word levels respectively. In other words, these findings indicate that mastering the vocabulary at those levels would potentially help the participants perform better on the IELTS academic reading test. This highlights the significant influence of vocabulary mastery at those levels on reading comprehension. Therefore, we believe that teaching the most frequent English words up to the 5,000word level is an important agenda for English teachers, especially those in the EFL or EMI settings.

\section{CONCLUSION}

In this study, we set out to investigate three things: the receptive vocabulary knowledge of Indonesian university students, their reading ability (as measured by the IELTS academic reading test), and the relationship between their scores on those two tests.

Our findings indicate that the participants had an insufficient size of vocabulary at all levels, potentially inhibiting their learning at the university that implements EMI policy. The participants also had a substandard reading proficiency, which would pose serious challenges for them as most of the learning materials at the university are provided in English. Finally, we found positive and significant correlations between the participants' scores on the IELTS academic reading test and the updated VLT at all levels, most notably at the 3,000 to 5,000-word levels. The large effect sizes also specifically highlight the important roles of vocabulary at the 3,000 to 5,000-word levels.

Several implications can be drawn from these findings. First, teachers and students need to dedicate their time to teaching and learning the vocabulary at the 1,000 to 5,000-word levels. The effect sizes of vocabulary mastery at some of those levels are perhaps too large to ignore. Second, it is also important for universities implementing EMI to set a minimum English proficiency standard as their admission requirement. Admitting students with poor English proficiency may put them at the risk of lagging behind their more fluent peers in their academic pursuits. Third, if setting a minimum level of English proficiency cannot be done, universities with EMI policy must ensure that assistance is provided for the students with low English proficiency. The assistance can be in the forms of providing EAP courses or language tutors, supporting English-related student clubs and activities, providing a writing center or self-access center, and promoting the use of English in daily communications. Finally, to add a more sense of urgency, we suggest that universities implementing EMI in Indonesia devise a policy setting a minimum language proficiency for their potential graduates. We believe that this would motivate students with low English proficiency to study the language more and hopefully improve their English.

Our study contributes to the growing body of literature on vocabulary research in three ways. First, our findings portray the level of receptive vocabulary knowledge of students from an Indonesian university implementing EMI. Findings describing the level of vocabulary knowledge of students in this setting is rare to be found in the literature. Many similar studies in the literature were either focused on the vocabulary knowledge of international students studying in English-speaking countries or the students studying in their home country with their mother tongue/ national language as the medium of instruction. Second, our findings highlight the importance of mastering intermediatelevel vocabulary in aiding reading comprehension in a standardized test. The large effect sizes found in this study indicate that knowledge of intermediatelevel vocabulary alone accounts for about a half of the variance of the IELTS reading score. Finally, our findings provide important information necessary in policy making in universities implementing EMI, especially those in Indonesia.

\section{ACKNOWLEDGEMENT}

We are grateful to the Ministry of Education, Culture, Research, and Technology (formerly the Minister of Research and Higher Education) for the 
research grant provided to fund this study. We are also thankful to the participants in this study.

\section{REFERENCES}

Aizawa, I., Rose, H., Thompson, G., \& Curle, S. (2020). Beyond the threshold: Exploring English language proficiency, linguistic challenges, and academic language skills of Japanese students in an English medium instruction programme. Language Teaching Research. https://doi.org/10.1177/1362168820965510

Ataş, U. (2018). The role of Receptive Vocabulary Knowledge in Advanced EFL Listening Comprehension. TESL-EJ, 21(4), 1-12.

Cahyono, B. Y., \& Widiati, U. (2015). The teaching of EFL vocabulary in the Indonesian context: the state of the art. TEFLIN Journal, 19(1), 117. https://doi.org/10.15639/teflinjournal.v19i1/117

Cambridge English Language Assessment. (2015). Cambridge IELTS 10. Cambridge University Press.

Dang, T. N. Y. (2020). Vietnamese Non-English major EFL University students' receptive knowledge of the most frequent English words. VNU Journal of Foreign Studies, 36(3), 1-11. https://doi.org/10.25073/25252445/vnufs. 4553

Dornyei, Z. (2007). Research methods in applied linguistics: Quantitative, qualitative, and mixed methodologies. Oxford University Press.

Durbahn, M., Rodgers, M., \& Peters, E. (2020). The relationship between vocabulary and viewing comprehension. System, 88, 102166. https://doi.org/10.1016/j.system.2019.102166

Gonzalez-Fernandez, B., \& Schmitt, N. (2017). Vocabulary acquisition. In S. Loewen \& M. Sato (Eds.), The Routledge handbook of instructed second language acquisition (pp. 280-298). Routledge. https://doi.org/10.4324/9781315676968.ch16

Grabe, W. (2009). Reading in a second language: moving from theory to practice. Cambridge University Press. https://doi.org/10.1017/CBO9781139150484

Ibrahim, E. H. E., Sarudin, I., \& Muhamad, A. J. (2016). The relationship between vocabulary size and reading comprehension of ESL learners. English Language Teaching, 9(2), 116-123. https://doi.org/10.5539/elt.v9n2p116

Kremmel, B., \& Schmitt, N. (2017). Vocabulary levels test. In J. I., Liontas (Ed.). The TESOL encyclopedia of English language teaching (Vol. 5, pp. 1-7). John Wiley \& Sons, Inc. https://doi.org/10.1002/9781118784235.eelt04 99

Kurniawan, I. (2017). Assessing English students` vocabulary size of Lampung State Islamic University. Humaniora, 8(4), 381-390. https://doi.org/10.21512/humaniora.v8i4.3909

Laflair, G. T., Egbert, J., \& Plonsky, L. (2015). A practical guide to bootstrapping descriptive statistics, correlations, T tests, and ANOVAS. In L. Plonsky (Ed). Advancing quantitative methods in second language research (pp. 4677). Routledge.

Larson-Hall, J. (2015). A guide to doing statistics in second language research using SPSS and $R$ (2nd ed.). Routledge. https://doi.org/10.4324/9781315775661

Li, L., \& MacGregor, L. J. (2010). Investigating the receptive vocabulary size of university-level Chinese learners of English: How suitable is the Vocabulary Levels Test? Language and Education, 24(3), 239-249. https://doi.org/10.1080/09500781003642478

Nation, I. (2006). How large a vocabulary is needed for reading and listening? Canadian Modern Language Review, 63(1), 59-82. https://doi.org/10.3138/cmlr.63.1.59

Nation, P., \& Meara, P. (2010). Vocabulary. In N. Schmitt (Ed.), An Introduction to applied linguistics (2nd ed., pp. 34-52). Hodder Education Publishers.

Nation, P., \& Waring, R. (1997). Vocabulary size, text coverage and word lists. In N. Schmitt \& M. McCarty (Eds.), Vocabulary: Description, acquisition and pedagogy (pp. 6-19). Cambridge University Press.

Nur, M. R., \& Madkur, A. (2014). Teachers' voices on the 2013 curriculum for English instructional activities. IJEE (Indonesian Journal of English Education), 1(2), 119-134. https://doi.org/10.15408/ijee.v1i2.1340

Nurweni, A., \& Read, J. (1999). The English vocabulary knowledge of Indonesian University students. English for Specific Purposes, 18(2), 161-175. https://doi.org/10.1016/S0889-4906(98)000052

Plonsky, L. (2015). Advancing quantitative methods in second language research (1st ed.). Routledge. https://doi.org/10.4324/9781315870908

Plonsky, L., Egbert, J., \& Laflair, G. T. (2014). Bootstrapping in applied linguistics: Assessing its potential using shared data. Applied Linguistics, 36(5), 591-610. https://doi.org/10.1093/applin/amu001

Riazi, A. M. (2016). The Routledge encyclopedia of research methods in applied linguistics. Routledge. https://doi.org/10.4324/9781315656762

Rose, H., Curle, S., Aizawa, I., \& Thompson, G. (2020). What drives success in English medium taught courses? The interplay between language proficiency, academic skills, and 
motivation. Studies in Higher Education, 45(11), 2149-2161. https://doi.org/10.1080/03075079.2019.159069 0

Rosenfeld, M., Leung, S., \& Oltman, P. K. (2001). The reading, writing, speaking and listening tasks important for academic success at the undergraduate and graduate levels. TOEFL monograph series (Vol. 21). Educational Testing Service

Schmitt, N. (2000). Vocabulary in Language teaching. Cambridge University Press.

Schmitt, N., Cobb, T., Horst, M., \& Schmitt, D. (2017). How much vocabulary is needed to use English? Replication of van Zeeland \& Schmitt (2012), Nation (2006) and Cobb (2007). Language Teaching, 50(2), 212-226. https://doi.org/10.1017/S0261444815000075

Schmitt, N., Jiang, X., \& Grabe, W. (2011). The percentage of words known in a text and reading comprehension. The Modern Language Journal, 95(1), 26-43. https://doi.org/10.1111/j.15404781.2011.01146.x

Schmitt, N., \& Schmitt, D. (2014). A reassessment of frequency and vocabulary size in L2 vocabulary teaching. Language Teaching, 47(4), 484-503. https://doi.org/10.1017/S0261444812000018

Schmitt, N., Schmitt, D., \& Clapham, C. (2001). Developing and exploring the behaviour of two new versions of the Vocabulary Levels Test. Language Testing, 18(1), 55-88. https://doi.org/10.1177/026553220101800103

Siregar, F. L. (2020). English students' vocabulary size and level at a Private University in West Java, Indonesia. Humaniora, 11(2), 75-81. https://doi.org/10.21512/humaniora.v11i2.6388

Sun, Y., \& Dang, T. N. Y. (2020). Vocabulary in high-school EFL textbooks: Texts and learner knowledge. System, 93, 102279. https://doi.org/10.1016/j.system.2020.102279

Susanto, A. (2017). Assessing the relationship between Vocabulary Level Test (VLT) and reading comprehension. Studies in English Language and Education, 4(2), 157-171. https://doi.org/10.24815/siele.v4i2.5118

Szabo, C. Z., Stickler, U., \& Adinolfi, L. (2020). Predicting the academic achievement of multilingual students of English through vocabulary testing. International Journal of Bilingual Education and Bilingualism. https://doi.org/10.1080/13670050.2020.181419 6

Uchihara, T., \& Harada, T. (2018). Roles of vocabulary knowledge for success in Englishmedium instruction: Self-perceptions and academic outcomes of Japanese undergraduates. TESOL Quarterly, 52(3), 564587. https://doi.org/10.1002/tesq.453

Webb, S., \& Nation, P. (2017). How vocabulary is learned. Oxford University Press.

Webb, S., Sasao, Y., \& Ballance, O. (2017). The updated Vocabulary Levels Test. ITL International Journal of Applied Linguistics, 168(1), 33-69. https://doi.org/10.1075/itl.168.1.02web

Woodrow, L. J. (2006). Academic success of international postgraduate education students and the role of English proficiency. University of Sydney Papers in TESOL, 1, 51-70.

Xing, P., \& Fulcher, G. (2007). Reliability assessment for two versions of Vocabulary Levels Tests. System, 35(2), 182-191. https://doi.org/10.1016/j.system.2006.12.009

Yen, D. A., \& Kuzma, J. (2009). Higher IELTS score, higher academic performance? The validity of IELTS in predicting the academic performance of Chinese students. Worcester Journal of Learning and Teaching, 3, 1-7. 